\title{
Effects of primary caregiver participation in vestibular rehabilitation for unilateral neglect patients with right hemispheric stroke: a randomized controlled trial
}

Neuropsychiatric Disease and Treatment

6 April 2013

Number of times this article has been viewed

\section{Chin-Ying Dai ${ }^{1,2}$ \\ Yu-Hui Huang ${ }^{3,4}$ \\ Li-Wei Chou ${ }^{5,6}$ \\ Shiao-Chi Wu ${ }^{7}$ \\ Ray-Yau Wang ${ }^{8}$ \\ Li-Chan Lin ${ }^{9}$}

'School of Nursing, National Yang Ming University, Taipei, Taiwan;

${ }^{2}$ Department of Nursing, Central

Taiwan University of Science and

Technology, Taichung, Taiwan;

${ }^{3}$ Department of Physical Medicine and Rehabilitation, Chung Shan

Medical University Hospital, Taichung,

Taiwan; ${ }^{4}$ School of Medicine, Chung

Shan Medical University, Taichung,

Taiwan; ${ }^{5}$ Department of Physical

Medicine and Rehabilitation, China

Medical University Hospital, Taichung,

Taiwan; ${ }^{6} \mathrm{School}$ of Chinese Medicine,

College of Chinese Medicine, China

Medical University, Taichung, Taiwan;

${ }^{7}$ Institute of Health and Welfare Policy,

National Yang-Ming University, Taipei,

Taiwan; ${ }^{8}$ Department of Physical

Therapy and Assistive Technology,

National Yang-Ming University, Taipei,

Taiwan; ${ }^{9}$ Institute of Clinical and

Community Health Nursing, National

Yang-Ming University, Taipei, Taiwan,

Republic of China

Correspondence: Li-Chan Lin Institute of Clinical and Community Health Nursing, National Yang-Ming University, 155 Li-Nong Street,

Sec 2, Beitou District, Taipei City

I I 221, Taiwan, Republic of China

Tel +8862 28267159

Fax +886228262997

Email lichan@ym.edu.tw
Introduction: The current study aims to investigate the effects of primary caregiver participation in vestibular rehabilitation (VR) on improving the measures of neglect, activities of daily living (ADL), balance, and falls of unilateral neglect (UN) patients.

Methods: This study is a single-blind randomized controlled trial. Both experimental $(n=24)$ and control groups $(n=24)$ received conventional rehabilitation. The experimental group undertook VR for a month. During the first and second weeks, a registered nurse trained the experimental group in VR. The primary caregivers in the experimental group supervised and guided their patients in VR during the third and fourth weeks. The outcome measures were neglect, ADL, balance, and falls.

Results: The two groups of UN patients showed a significant improvement in neglect, ADL, and balance over time. Based on the generalized estimating equations model, an interaction was observed between groups and times. Significant interactions were observed between the VR group at days 14 and 28 in the areas of neglect, ADL, and balance. No significant difference was observed between the two groups in the number of falls.

Conclusion: Neglect, ADL, and balance among UN patients with right hemispheric stroke can be improved through the participation of primary caregivers in VR. Trained informal caregivers were recommended to provide VR guidance and supervision to patients who suffer from UN. Keywords: neglect, vestibular rehabilitation, falls, balance, caregiver

\section{Introduction}

The term "unilateral neglect" (UN) or "neglect" refers to the condition in which patients are unable to report, respond, or orient themselves to meaningful stimuli in the contralesional side of space after a brain lesion that cannot be attributed to sensory or motor dysfunction. ${ }^{1}$ The common behaviors associated with UN include eye and head deviation toward the ipsilesional side, ignoring or not paying attention to people and things on the contralesional side, and bumping into objects placed on the contralesional side., ${ }^{1,2}$ Patients may recover from UN spontaneously; however, some patients cannot recover naturally, which has been a long-standing medical problem. ${ }^{3,4}$ Patients with right hemispheric stroke are more prone to UN with severe clinical outcomes. The prevalence of UN among these patients ranges from $29 \%$ to $82 \%$ during acute hospitalization, ${ }^{5,6}$ and from $13 \%$ to $69 \%$ in rehabilitation units. ${ }^{7,8} \mathrm{UN}$ has the following effects on stroke patients: it hinders their activities of daily living (ADL), ${ }^{9}$ reduces their health-related quality of life, ${ }^{10}$ increases their fall hazard ratio 
by 1.5 times, ${ }^{11}$ and increases the duration of rehabilitation in the hospital by 10 to 40 days. ${ }^{9,12}$ Moreover, approximately $80 \%$ of patients after discharge still need assistance from caregivers. $^{9}$

The vestibular system contributes to a wide range of functions, from postural and oculomotor reflexes to spatial representation and cognition. ${ }^{13}$ Karnath and Dieterich ${ }^{2}$ found that healthy subjects may show symptoms similar to UN after unilateral vestibular stimulation, such as the deviation of the eyes and/or head to the ipsilateral side. Both spatial neglect and vestibular processing at the cortical level show dominance in the right hemisphere and involve common brain areas. Thus, Karnath and Dieterich ${ }^{2}$ argued that these cortical areas are not strictly part of the vestibular system, but rather have a multimodal character, representing a significant site for the neural transformation of converging vestibular, auditory, as well as neck proprioceptive and visual input into higher-order spatial representations. Therefore, UN may be highly related to the dysfunctions of the integrated vestibular system or of various types of sensory inputs. Based on a systematic review, caloric vestibular stimulation with leftward nystagmus was found to significantly ameliorate the left UN on several neglect tasks, albeit only for a short period. ${ }^{14}$ Other sensory stimulations have also been used as rehabilitation methods capable of reducing UN symptoms. These sensory stimulations include trunk rotation (TR), ${ }^{15,16}$ optokinetic stimulation (OKS), ${ }^{17,18}$ and neck muscle vibration (NMV). ${ }^{18-20}$

TR as an intervention has been used in studies with randomized controlled trials. ${ }^{15,16} \mathrm{TR}$ involves training the patient to use a Bon Saint Come device and visualize a pointer by doing trunk rotation, ${ }^{15}$ or to use a traditional set-up device and move across the midline of the body to the contralesional space by visual spatial motor cueing. ${ }^{16}$ Wiart et $\mathrm{al}^{15}$ indicated that 1 month of TR could reduce neglect and improve ADL; however, Fong et $\mathrm{al}^{16}$ showed that TR failed to reduce neglect and improve ADL. The designs, numbers of cases, and intervention periods of these two studies were similar; nevertheless, their outcomes were different, probably because the patients performed different types of TR with different devices. OKS involves the use of a computer program that exposes the patient to an optokinetic stimulus represented by a field of small randomly spaced squares moving to the left. ${ }^{18}$ A number of studies have indicated that OKS can effectively improve neglect. ${ }^{17,18} \mathrm{NMV}$ involved the patients undergoing transcutaneous electrical nerve stimulation on the left posterior neck muscles. ${ }^{18}$ A number of studies have confirmed that NMV can effectively reduce neglect. ${ }^{18-20}$
The interventional methods (TR, OKS, and NMV) employed in these studies require different instruments and can result in different effects; thus, they are not conducive to broad application by health care professionals (such as nurses and therapists) in bedside operations, and they may not be implemented by the patients themselves. However, vestibular rehabilitation (VR) is a method for stimulating the vestibular functions, and this is a simple and safe intervention and can be trained without instruments. Based on a number of studies, patients with peripheral or central vestibular dysfunction can effectively improve their dizziness, balance, and ADL through VR training. ${ }^{21-24}$ According to Osawa and Maeshima, ${ }^{25}$ involving family caregivers in patients' bedside care (such as standup and gait exercises, as well as transfers from chair to chair) can effectively increase ADL and reduce neglect. Considering a severe shortage of nurses in Taiwan in recent years, the objective of this study is to find out if the participation of primary caregivers in VR can improve ADL and balance, and reduce neglect and falls.

\section{Materials and methods Design}

This study adopts a single-blind experimental design, by which the patients knew which group (experimental or control group) they are enrolled in. Two physiotherapists assessed the patients' data via the blinding method.

The research sites were the rehabilitation wards of two medical centers located in central Taiwan. The wards of the same hospital were randomly assigned to the experimental or control group to avoid confounding effects on the intervention in both groups. The inclusion criteria for the stroke subjects include: (1) being diagnosed by physicians, computed tomography, or magnetic resonance imaging scan of the brain as having experienced a right hemispheric stroke, including hemorrhagic or ischemic strokes, and first-time stroke with a duration of less than 6 months from the stroke onset; (2) meeting the conditions for neglect on any of the two scales within the Behavioral Inattention Test Conventional (BITC) subtest; and (3) capable of communicating in Mandarin Chinese or Taiwanese, and understanding instructions. The inclusion criteria for the primary caregivers include: (1) being defined as primary caregivers by patients during inpatient rehabilitation, including family members, friends, employed nursing aides, and foreign caregivers; (2) willing to participate in supervising and guiding the patients' VR training; and (3) capable of communicating in Mandarin Chinese or Taiwanese. The exclusion criteria were recurrent stroke with duration of more than 6 months from stroke onset, less than 
two subtests (BITC) of diagnosed neglect, incapability to communicate, and lack of primary caregivers.

\section{Procedures}

The study protocol was approved by the institutional review boards of the participating medical centers. The researchers explained the procedures to the patients and their primary caregivers, and obtained their written consent. During the first and second weeks, a registered nurse (RN) trained the patients in VR. The training was provided once per day for 30 minutes, for a total of ten sessions over 2 weeks. During the third and fourth weeks, the patients were supervised and guided in VR by their primary caregivers. During the first week, the RN also taught the primary caregivers how to supervise and guide the patients' VR. Each session lasted for approximately 5 minutes to 10 minutes, with the primary caregivers requiring two to four sessions (approximately 20 minutes to 40 minutes in total) before being able to supervise and guide the patients' VR correctly.

The control and the experimental groups both received conventional rehabilitation. Data collection was conducted at three time points: day 0 , before the VR intervention (baseline); day 14, the second week of the intervention; and day 28 , the fourth week of the intervention (Table 1).

\section{VR protocol}

The Cawthorne-Cooksey exercises are the most widely used VR method. Portions of the Cawthorne-Cooksey exercises were used in our VR protocol design. The protocol involved side-to-side head turns, up-and-down head movements, and gaze movements. ${ }^{23,24}$ The VR trainer is an RN with several years of experience in taking care of patients with stroke, and the $\mathrm{RN}$ has been trained for 3 hours by a physiotherapist responsible for the VR training.

In the course of the exercise, the patients were seated in a wheelchair and their heads and bodies were in the

Table I Study design

\begin{tabular}{|c|c|c|c|c|c|}
\hline & Day & $\begin{array}{l}\text { Ist- } \\
\text { 2nd week }\end{array}$ & 4 & $\begin{array}{l}\text { 3rd- } \\
\text { 4th week }\end{array}$ & ay 28 \\
\hline $\begin{array}{l}\text { VR } \\
\text { group }\end{array}$ & Pretest* & $\begin{array}{l}\mathrm{RN} V \mathrm{R}+ \\
\mathrm{CT}\end{array}$ & Follow-up I* & $\begin{array}{l}\text { Caregiver } \\
\text { VR + CT }\end{array}$ & rollow-up ${ }^{*}$ \\
\hline $\begin{array}{l}\text { Control } \\
\text { group }\end{array}$ & Pretest* & $\mathrm{CT}$ & Follow-up I* & $\mathrm{CT}$ & Follow-up $2^{*}$ \\
\hline \multicolumn{6}{|c|}{$\begin{array}{l}\text { Note: *The outcomes measured included } A D L\left(\text { FIM }^{\circledR}\right) \text {, neglect }(B I T C) \text {, balance } \\
\text { (PASS), and falls. } \\
\text { Abbreviations: VR, vestibular rehabilitation; RN, registered nurse; CT, conventional } \\
\text { therapy; ADL, activities of daily living; FIM }{ }^{\circledR} \text {, Functional Independence Measure }{ }^{\circledR} \text {; } \\
\text { BITC, Behavioral Inattention Test Conventional; PASS, Postural Assessment Scale } \\
\text { for Stroke patients. }\end{array}$} \\
\hline
\end{tabular}

middle position. During the training process, the patients were typically less active on their neglected sides, and their head and neck postures tended to slant. The instructors verbally reminded the patients to maintain their heads and bodies in the middle position. The gaze target was pasted on a $60 \mathrm{~cm}$ long and $20 \mathrm{~cm}$ wide white polypropylene corrugated board. The target size was determined by the patients' vision. In most cases, a $2 \mathrm{~cm}$ colored dot was used as the target.

The VR training procedure is described as follows: (1) with their eyes open, the patients moved their head up and down for 20 times or for 1 minute. They also moved their head from side to side for 20 times or for 1 minute. (2) With their eyes closed, the patients moved their head up and down for 20 times or for 1 minute. They also moved their head from side to side for 20 times or for 1 minute. (3) The polypropylene corrugated board was placed on the trainers' thighs. The target was at the same height as the patients' eyes. The patients gazed at the target while moving their head up and down and from side to side for 20 times. (4) The patients rested as necessary. The patients performed steps one to three repeatedly, and the entire process took approximately 30 minutes.

\section{Conventional rehabilitation}

Both the experimental and control groups received the same conventional rehabilitation. The patients were required to spend 2 hours on conventional rehabilitation - specifically, 1 hour for physical therapy and 1 hour for occupational therapy - for a total of 5 days a week. The exercise training for the physical therapy included passive exercises, active exercises, resistive exercises, ambulation training, and so on. The occupational therapy included maintaining or improving physiological functions such as endurance, balance, and training, to improve ADL, such as dressing, using the toilet, sanitation, home care, and others.

\section{Outcome measures}

UN was measured by the conventional subtests (BITC) of the Rivermead Behavioral Inattention Test, which involved six traditional paper-and-pencil exercises: representation drawing, figure and shape copying, line bisection, line crossing, star cancellation, and letter cancellation. Higher scores indicate lighter UN. This scale possesses excellent reliability and validity. ${ }^{5,26,27}$

ADL was assessed with the Functional Independence Measure $\left(\mathrm{FIM}^{\circledR}\right)$ instrument (Uniform Data System for Medical Rehabilitation, Amherst, NY, USA). The measure included 18 items covering six functional domains: self-care, sphincter control, transfers, locomotion, communication, and 
social cognition. All items on the $\mathrm{FIM}^{\circledR}$ instrument were measured on seven ordinal levels ranging from 1 (total assistance) to 7 (complete independence). The reliability and validity of the FIM ${ }^{\circledR}$ instrument have been studied extensively in patients with stroke, and at rehabilitation facilities..$^{28,29}$

Balance was measured using the Postural Assessment Scale for Stroke patients (PASS), which is suitable for assessing the patients' balance in various situations. Higher scores indicate that the patients have superior balancing capabilities. The scale has excellent reliability and validity. ${ }^{30,31}$

Falls were defined as involuntarily tripping, falling or slipping, and unexpected drops to the ground or lower positions. Falls also included an unexpectedly slanting downward position when the patient is standing, sitting, or walking, and can include unintentional changes in posture that result in contact between the body and the ground. ${ }^{32,33}$ In this study, the stroke patients and their caregivers reported the number of falls. These incidences were recorded and checked with a nurse.

\section{Statistical analysis}

Data were analyzed using the Statistical Package for the Social Sciences 15 (IBM Corporation, Armonk, NY, USA). The significance level was set at 0.05 . Descriptive statistics were used to describe the sample profile. The difference between groups was analyzed via an independent $t$-test and chi-square test. The changes in the outcomes over time were analyzed using a one-way repeated measures analysis of variance test. The Bonferroni test was also carried out for post hoc analyses. Group and time interaction effects were tested using the generalized estimating equations model, which considered the dependency of our data and yielded an unbiased $P$-value.

\section{Results}

Initially, $55 \mathrm{UN}$ patients with right hemispheric stroke were randomly assigned to the VR or control group. Three patients withdrew from the VR group and four discontinued in the control group; hence, a total of 24 patients in each group were included in the data analysis (see Figure 1). The age of the patients ranged from 30 years to 87 years, and the average age of the 48 patients was 60.88 years $(\mathrm{SD}=13.87)$. The number of days after the stroke ranged from 15 days to 155 days, and the average number of days after the stroke was 65.38 (SD 38.95). Table 2 shows that the two groups do not differ significantly in age, gender, participating caregiver attributes, number of days since stroke, and cognitive functioning.

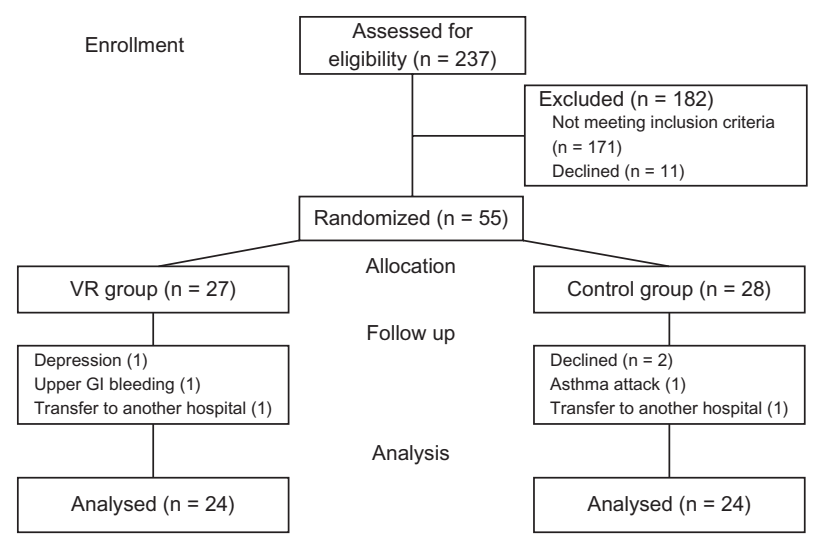

Figure I Flowchart of participants.

Abbreviations: $n$, number; VR, vestibular rehabilitation; GI, gastrointestinal.

The independent $t$-test was used to determine whether the outcome measurements from the two groups differed significantly. The results indicated that the two groups did not differ significantly in BITC, FIM ${ }^{\circledR}$, PASS, and falls at baseline (day 0 ), day 14 , and day 28 . Using one-way repeated measures analysis of variance to test the BITC, FIM ${ }^{\circledR}$, and PASS of the VR group or the control group at day 0 , day 14 , and day 28 , we found significant improvements over time $(P<0.00)$. A post-hoc test indicated that BITC, FIM ${ }^{\circledR}$, and PASS scores at day 28 were higher than at day 0 and day 14 , and scores at day 14 were higher than at day 0 in the VR and control groups. The two groups did not differ significantly in the number of falls at day 0 , day 14 , and day 28 (Table 3 ).

Table 4 shows that the main effect of the generalized estimating equations model demonstrated no significant difference between the VR and control groups; however, the scores of FIM ${ }^{\circledR}$, BITC, and PASS on day 14 and day 28 were significantly higher than those on day 0 . Moreover, an interaction effect was observed between the VR group and times (at day 14 and at day 28). The slopes were increased by 15.46 and 18.96 for the BITC scores, respectively $(P=0.011$; $P=0.009$, respectively); by 8.13 and 9.38 for the $\mathrm{FIM}^{\circledR}$ scores, respectively $(P=0.011 ; P=0.011$, respectively); and by 4.42 and 4.63 for the PASS scores, respectively ( $P=0.001 ; P=0.003$, respectively) (see Table 4). Overall, the ADL, neglect, and balance of the two groups improved in the trial period for 1 month. The VR group indicated a more significant improvement than the control group.

\section{Discussion}

The results indicate that the neglect, ADL, and balance of UN patients with right hemispheric stroke can be improved by performing 30 minutes of VR for 5 days a week for 4 weeks; however, VR cannot reduce the number of falls. This study 
Table 2 Summary of sample characteristics

\begin{tabular}{|c|c|c|c|c|c|c|}
\hline \multirow[t]{2}{*}{ Characteristics } & \multicolumn{2}{|l|}{ VR $(n=24)$} & \multicolumn{2}{|c|}{ Control $(n=24)$} & \multirow[t]{2}{*}{$t^{\mathrm{a} /} \chi^{2 \mathrm{~b}}$} & \multirow[t]{2}{*}{$P$} \\
\hline & $M \pm S D$ & n (\%) & $M \pm S D$ & n (\%) & & \\
\hline Age & $57.21 \pm 12.23$ & & $64.54 \pm 14.67$ & & $1.88 \mathrm{I}^{\mathrm{a}}$ & 0.066 \\
\hline Duration from stroke onset & $56.88 \pm 38.93$ & & $73.88 \pm 37.86$ & & $1.533^{\mathrm{a}}$ & 0.132 \\
\hline MMSE & $19.38 \pm 4.92$ & & $17.38 \pm 4.14$ & & $-1.525^{a}$ & 0.134 \\
\hline Gender & & & & & $0.242^{b}$ & 0.380 \\
\hline Male & & $16(66.67)$ & & $12(50.00)$ & & \\
\hline Female & & $8(33.33)$ & & $12(50.00)$ & & \\
\hline Participant caregiver & & & & & $0.155^{b}$ & 0.926 \\
\hline Family & & $8(33.33)$ & & $8(33.33)$ & & \\
\hline Nursing attendants & & $12(50.00)$ & & II (45.84) & & \\
\hline Foreign caregivers & & $4(16.67)$ & & $5(20.83)$ & & \\
\hline
\end{tabular}

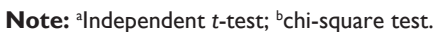

Abbreviations: VR, vestibular rehabilitation; M, mean; SD, standard deviation; n, number; MMSE, Mini-Mental State Examination.

reveals a high feasibility for primary caregivers' guidance and supervision of patients in VR. Primary caregivers can guide and supervise patients in VR after receiving instruction from an $\mathrm{RN}$, and observing their patients for two to four VR sessions. Although almost half of the patients experienced slight dizziness during VR, it was tolerable and disappeared once the movements were ceased. In the beginning, approximately four-fifths of the patients had severe gaze deviation and were unable to participate in the gaze training. At the end of the experiment, two-thirds of the patients continued to experience gaze deviation. These patients had comparatively severe levels of neglect. Therefore, we recommend eliminating the gaze training from the VR training to increase the ease of bedside VR implementation.
In the Taiwanese health care system, informal caregivers typically assist patients in their ADL. All of the patients in this study had primary caregivers. Only one primary family caregiver refused to participate in this study. After the patients received the VR training, their primary caregivers said that the transferring and walking of the patients became easier with the caregiver's assistance. The reason was that the patients' bodies tended not to lean to the ipsilesional or contralesional side. The majority of the primary caregivers in this study were willing to participate in the patients' VR programs. Therefore, the rehabilitation team could involve informal caregivers in the VR training.

Considering the efficacy of the VR training on neglect, the BITC scores of the VR group were significantly higher

Table 3 Comparison of the VR and the control groups in the outcome measures

\begin{tabular}{|c|c|c|c|c|c|}
\hline \multirow[t]{2}{*}{ Item } & \multirow{2}{*}{$\frac{\text { Day } 0}{M \pm S D}$} & \multirow{2}{*}{$\frac{\text { Day I4 }}{M \pm \text { SD }}$} & \multirow{2}{*}{$\frac{\text { Day } 28}{M \pm \text { SD }}$} & \multirow[t]{2}{*}{$P a$} & \multirow[t]{2}{*}{ Post hoc ${ }^{b}$} \\
\hline & & & & & \\
\hline \multicolumn{6}{|c|}{ Neglect (BITC) } \\
\hline VR & $49.71 \pm 39.63$ & $76.54 \pm 44.04$ & $88.7 I \pm 44.56$ & 0.000 & $3>2, I ; 2>I^{c}$ \\
\hline Control & $48.79 \pm 44.64$ & $60.17 \pm 45.95$ & $68.83 \pm 44.72$ & 0.000 & $3>2, I ; 2>I^{c}$ \\
\hline$P^{\mathrm{d}}$ & 0.840 & 0.214 & 0.130 & & \\
\hline \multicolumn{6}{|l|}{ ADL $\left(\mathrm{FIM}^{\circledR}\right)$} \\
\hline VR & $58.08 \pm 20.59$ & $71.63 \pm 22.70$ & $76.21 \pm 23.08$ & 0.000 & $3>2, I ; 2>I^{c}$ \\
\hline Control & $56.42 \pm 20.10$ & $61.83 \pm 21.45$ & $65.17 \pm 21.55$ & 0.000 & $3>2, I ; 2>I^{c}$ \\
\hline$P^{\mathrm{d}}$ & 0.778 & 0.131 & 0.093 & & \\
\hline \multicolumn{6}{|c|}{ Balance (PASS) } \\
\hline VR & $12.88 \pm 9.09$ & $19.29 \pm 7.88$ & $21.54 \pm 7.16$ & 0.000 & $3>2, I ; 2>I^{c}$ \\
\hline Control & $\mid 4.00 \pm 8.11$ & $16.00 \pm 7.43$ & $18.04 \pm 7.04$ & 0.000 & $3>2, I ; 2>I^{c}$ \\
\hline$P^{d}$ & 0.653 & 0.143 & 0.094 & & \\
\hline \multicolumn{6}{|l|}{ Fall } \\
\hline VR & $0.25 \pm 0.53$ & $0.04 \pm 0.20$ & $0.04 \pm 0.20$ & 0.080 & \\
\hline Control & $0.29 \pm 0.62$ & $0.13 \pm 0.34$ & $0.08 \pm 0.28$ & 0.123 & \\
\hline$P^{\mathrm{d}}$ & 0.804 & 0.306 & 0.561 & & \\
\hline
\end{tabular}

Notes: aOne-way repeated measures ANOVA; bpost hoc: Bonferroni method; 'day 0: I; day 14: 2; day 28: 3; dindependent $t$-test.

Abbreviations: VR, vestibular rehabilitation; M, mean; SD, standard deviation; BITC, Behavioral Inattention Test Conventional; ADL, activities of daily living; FIM ${ }^{\circledR}$, Functional Independence Measure ${ }^{\circledR}$; PASS, Postural Assessment Scale for Stroke patients; ANOVA, analysis of variance. 
Table 4 GEE model evaluation of comparison between groups and times

\begin{tabular}{|c|c|c|c|c|c|c|}
\hline \multirow[t]{2}{*}{ Item } & \multirow[t]{2}{*}{$\beta^{a}$} & \multirow[t]{2}{*}{ SE } & \multicolumn{2}{|l|}{$95 \% \mathrm{Cl}$} & \multirow{2}{*}{$\begin{array}{l}\text { Wald } \\
\text { Chi-square }\end{array}$} & \multirow[t]{2}{*}{$P$} \\
\hline & & & Lower & Upper & & \\
\hline \multicolumn{7}{|c|}{ Neglect (BITC) } \\
\hline Intercept & 48.79 & 8.92 & 31.31 & 66.28 & 29.91 & 0.000 \\
\hline Group $^{b}$ & 0.92 & 11.93 & -22.47 & 24.30 & 0.01 & 0.939 \\
\hline Time (Day I4) & 11.38 & 3.79 & 3.94 & 18.81 & 9.00 & 0.003 \\
\hline Time (Day 28) ${ }^{\mathrm{b}}$ & 20.04 & 4.00 & 12.21 & 27.88 & 25.14 & 0.000 \\
\hline VR $\times$ Day $14^{b}$ & 15.46 & 6.10 & 3.50 & 27.42 & 6.42 & 0.011 \\
\hline $\mathrm{VR} \times$ Day $28^{\mathrm{b}}$ & 18.96 & 7.28 & 4.69 & 33.23 & 6.78 & 0.009 \\
\hline \multicolumn{7}{|l|}{ ADL (FIM $\left.{ }^{\circledR}\right)$} \\
\hline Intercept & 56.42 & 4.02 & 48.55 & 64.29 & 197.30 & 0.000 \\
\hline Group $^{\mathrm{b}}$ & 1.67 & 5.75 & -9.60 & 12.94 & 0.08 & 0.772 \\
\hline Time (Day I4) & 5.42 & 1.52 & 2.44 & 8.39 & 12.73 & 0.000 \\
\hline Time (Day 28$)^{b}$ & 8.75 & 1.87 & 5.08 & 12.42 & 21.87 & 0.000 \\
\hline VR $\times$ Day $14^{b}$ & 8.13 & 3.19 & 1.88 & 14.37 & 6.50 & 0.011 \\
\hline $\mathrm{VR} \times$ Day $28^{\mathrm{b}}$ & 9.38 & 3.67 & 2.18 & 16.58 & 6.51 & 0.011 \\
\hline \multicolumn{7}{|c|}{ Balance (PASS) } \\
\hline Intercept & 14.00 & 1.62 & 10.82 & 17.18 & 74.57 & 0.000 \\
\hline Group $^{\mathrm{b}}$ & -1.13 & 2.43 & -5.90 & 3.65 & 0.21 & 0.644 \\
\hline Time (Day I4) & 2.00 & 0.52 & 0.98 & 3.02 & 14.77 & 0.000 \\
\hline Time (Day 28$)^{\mathrm{b}}$ & 4.04 & 0.82 & 2.44 & 5.64 & 24.44 & 0.000 \\
\hline $\mathrm{VR} \times$ Day $14^{\mathrm{b}}$ & 4.42 & 1.30 & 1.88 & 6.96 & 11.61 & 0.001 \\
\hline VR $\times$ Day $28^{b}$ & 4.63 & 1.55 & 1.60 & 7.66 & 8.95 & 0.003 \\
\hline
\end{tabular}

Note: aRegression coefficient; ' ${ }^{b}$ control group (or Day 0 ) is the reference. Abbreviations: GEE, generalized estimating equations; SE, standard error; $\mathrm{Cl}$, confidence interval; BITC, Behavioral Inattention Test Conventional; VR, vestibular rehabilitation; ADL, activities of daily living; FIM ${ }^{\circledR}$, Functional Independence Measure ${ }^{\circledR}$; PASS, Postural Assessment Scale for Stroke patients.

on days 14 and 28 compared with day 0 . Similar studies have indicated that sensory stimulation, as an intervention (such as TR, OKS, and NMV), could reduce neglect. ${ }^{15,17-20}$ The FIM $^{\circledR}$ scores of the VR group on days 14 and 28 are higher than those of the control group. The effect of the VR on UN patients was similar to that of other interventions such as TR and NMV. ${ }^{15,19}$ With central or peripheral vestibular dysfunction, such as that exhibited by patients with brainstem lesions combined with vertigo, simple VR - such as head movement training - can improve ADL..$^{23,34}$ In this study, the majority of the patients' heads were deviated toward the ipsilesional side before the VR. After performing the up-anddown head movements, this condition was clearly improved. The patients' balance and ADL may have improved because the problem of head deviation was corrected. Based on the studies described previously, various sensory stimulation and VR interventions are conducive to an increase in the ADL of UN patients. However, a systematic review that conducted a meta-analysis of various interventions based on different neglect theories, such as visual scanning, Fresnel prisms, active limb activation, TR, and cueing spatiomotor and perceptual tasks, found no effect on the ADL of UN patients. ${ }^{35}$
Therefore, using the dysfunctions of the integration of the vestibular system or disorders of various sensory input as a theoretical foundation, an intervention designed based on the transformation deficit theory could be more effective in improving the ADL of UN patients.

The results of this study indicate that the balance (PASS) of the VR group improved more significantly than that of the control group; however, the two groups did not differ in terms of the number of falls. Ertekin et a ${ }^{36}$ reported no significant difference in balance for UN patients, regardless of whether conventional physical therapy was conducted by physiotherapists in a hospital or by the patients themselves at home. Other studies have revealed that the communitybased VR training for the elderly patients with dizziness or instability of gait could improve their balance and reduce the risk factors of falls. ${ }^{37-39}$ Nevertheless, Hansson et a ${ }^{38}$ found that VR did not reduce the number of falls among dizzy patients. Previous studies on interventions for UN patients have rarely used balance and falls as the outcome measure; therefore, the effects of VR training on the balance and falls of UN patients requires further investigation.

The limitations of this study are that the participants could not be blinded to their treatment status, and the study included only patients who were hospitalized, conscious, had a right hemispheric stroke, and had caregivers. These results could not be generalized to all stroke patients. An additional limitation is that the direct effect of VR on the falls requires further clarification. This study found that VR may not reduce the number of falls when patients were supervised by caregivers. Given the multiple risk factors of falls, we suggest an assessment of the risk factors of falls and the instability of gait, or an extension of the period of study in future research.

\section{Conclusion}

The results of this study indicate that the neglect, ADL, and balance of UN patients with right hemispheric stroke can be improved through the participation of primary caregivers in VR; however, no significant effects were observed in the number of falls. VR is feasible for clinical application. Nearly all hospitalized stroke patients in Taiwan have informal caregivers to assist in their ADL. These informal caregivers could guide and supervise patients in VR after receiving brief (20-minute to 40-minute) training from RNs.

\section{Acknowledgments}

We would like to thank the China Medical University Hospital and the East District Branch, as well as the Chung Shan Medical University Hospital and the Chung Shing Branch. 


\section{Disclosure}

The authors report no conflicts of interest in this work. No commercial party having a direct financial interest in the results of the research supporting this article has or will confer a benefit upon the authors or upon any organization with which the authors are associated.

\section{References}

1. Heilman KM, Watson RT, Valenstein E. Neglect and related disorders. In: Heilman KM, Valenstein E, editors. Clinical Neuropsychology. 2th ed. New York: Oxford University Press; 1985. P243-293.

2. Karnath HO, Dieterich M. Spatial neglect - a vestibular disorder? Brain. 2006;129(Pt 2):293-305.

3. Farnè A, Buxbaum LJ, Ferraro M, et al. Patterns of spontaneous recovery of neglect and associated disorders in acute right brain-damaged patients. J Neurol Neurosurg Psychiatry. 2004;75(10):1401-1410.

4. Jehkonen M, Laihosalo M, Koivisto AM, Dastidar P, Ahonen JP. Fluctuation in spontaneous recovery of left visual neglect: a 1-year follow-up. Eur Neurol. 2007;58(4):210-214.

5. Jehkonen M, Ahonen J, Dastidar P, et al. Visual neglect as a predictor of functional outcome one year after stroke. Acta Neurol Scand. 2000; 101(3):195-201.

6. Stone SP, Halligan PW, Greenwood RJ. The incidence of neglect phenomena and related disorders in patients with an acute right or left hemisphere stroke. Age Ageing. 1993;22(1):46-52.

7. Cherney LR, Halper AS, Kwasnica CM, Harvey RL, Zhang M. Recovery of functional status after right hemisphere stroke: relationship with unilateral neglect. Arch Phys Med Rehabil. 2001;82(3):322-328.

8. Sunderland A, Wade DT, Langton Hewer R. The natural history of visual neglect after stroke. Indications from two methods of assessment. Int Disabil Stud. 1987;9(2):55-59.

9. Katz N, Hartman-Maeir A, Ring H, Soroker N. Functional disability and rehabilitation outcome in right hemisphere damaged patients with and without unilateral spatial neglect. Arch Phys Med Rehabil. 1999; 80(4):379-384.

10. Franceschini M, La Porta F, Agosti M, Massucci M; for ICR2 group. Is health-related-quality of life of stroke patients influenced by neurological impairments at one year after stroke? Eur J Phys Rehabil Med. 2010;46(3):389-399.

11. Czernuszenko A, Czlonkowska A. Risk factors for falls in stroke patients during inpatient rehabilitation. Clin Rehabil. 2009;23(2):176-188.

12. Gillen R, Tennen H, McKee T. Unilateral spatial neglect: relation to rehabilitation outcomes in patients with right hemisphere stroke. Arch Phys Med Rehabil. 2005;86(4):763-767.

13. Borel L, Lopez C, Péruch P, Lacour M. Vestibular syndrome: a change in internal spatial representation. Neurophysiol Clin. 2008;38(6): 375-389.

14. Luauté J, Halligan P, Rode G, Rossetti Y, Boisson D. Visuo-spatial neglect: a systematic review of current interventions and their effectiveness. Neurosci Biobehav Rev. 2006;30(7):961-982.

15. Wiart L, Côme AB, Debelleix X, et al. Unilateral neglect syndrome rehabilitation by trunk rotation and scanning training. Arch Phys Med Rehabil. 1997;78(4):424-429.

16. Fong KN, Chan MK, Ng PP, et al. The effect of voluntary trunk rotation and half-field eye-patching for patients with unilateral neglect in stroke: a randomized controlled trial. Clin Rehabil. 2007;21(8):729-741.

17. Kerkhoff G, Keller I, Ritter V, Marquardt C. Repetitive optokinetic stimulation induces lasting recovery from visual neglect. Restor Neurol Neurosci. 2006;24(4-6):357-369.

18. Schröder A, Wist ER, Hömberg V. TENS and optokinetic stimulation in neglect therapy after cerebrovascular accident: a randomized controlled study. Eur J Neurol. 2008;15(9):922-927.
19. Kamada K, Shimodozono M, Hamada H, Kawahira K. Effects of 5 minutes of neck-muscle vibration immediately before occupational therapy on unilateral spatial neglect. Disabil Rehabil. 2011; 33(23-24):2322-2328.

20. Johannsen L, Ackermann H, Karnath HO. Lasting amelioration of spatial neglect by treatment with neck muscle vibration even without concurrent training. J Rehabil Med. 2003;35(6):249-253.

21. Hillier SL, Hollohan V. Vestibular rehabilitation for unilateral peripheral vestibular dysfunction. Cochrane Database Syst Rev. 2007;4:CD005397.

22. Hansson EE, Månsson NO, Håkansson A. Effects of specific rehabilitation for dizziness among patients in primary health care: a randomized controlled trial. Clin Rehabil. 2004;18(5):558-565.

23. Cohen H. Vestibular rehabilitation reduces functional disability. Otolaryngol Head Neck Surg. 1992;107(5):638-643.

24. Yardley L, Donovan-Hall M, Smith HE, Walsh BM, Mullee M, Bronstein AM. Effectiveness of primary care-based vestibular rehabilitation for chronic dizziness. Ann Intern Med. 2004;141(8):598-605.

25. Osawa A, Maeshima S. Family participation can improve unilateral spatial neglect in patients with acute right hemispheric stroke. Eur Neurol. 2010;63(3):170-175.

26. Hartman-Maeir A, Katz N. Validity of the Behavioral Inattention Test (BIT): relationships with functional tasks. Am J Occup Ther. 1995; 49(6):507-516.

27. Wilson B, Cockburn J, Halligan P. Development of a behavioral test of visuospatial neglect. Arch Phys Med Rehabil. 1987;68(2):98-102.

28. Hamilton BB, Laughlin JA, Fiedler RC, Granger CV. Interrater reliability of the 7-level functional independence measure (FIM). Scand J Rehabil Med. 1994;26(3):115-119.

29. Ottenbacher KJ, Hsu Y, Granger CV, Fiedler RC. The reliability of the functional independence measure: a quantitative review. Arch Phys Med Rehabil. 1996;77(12):1226-1232.

30. Benaim C, Pérennou DA, Villy J, Rousseaux M, Pelissier JY. Validation of a standardized assessment of postural control in stroke patients: the Postural Assessment Scale for Stroke Patients (PASS). Stroke. 1999; 30(9):1862-1868.

31. Wang CH, Mao HF, Hsueh IP, Hsieh CL. The psychometric characteristics of the postural assessment scale for stroke patients. Formosan J Med. 2002;6(4):474-482. Chinese.

32. Simpson LA, Miller WC, Eng JJ. Effect of stroke on fall rate, location and predictors: a prospective comparison of older adults with and without stroke. PLoS One. 2011;6(4):e19431.

33. Forster A, Young J. Incidence and consequences of falls due to stroke: a systematic inquiry. BMJ. 1995;311(6997):83-86.

34. Cohen H, Kane-Wineland M, Miller LV, Hatfield CL. Occupation and visual/vestibular interaction in vestibular rehabilitation. Otolaryngol Head Neck Surg. 1995;112(4):526-532.

35. Bowen A, Lincoln NB. Cognitive rehabilitation for spatial neglect following stroke. Cochrane Database Syst Rev. 2007;2:CD003586.

36. Ertekin ÖA, Gelecek N, Yildirim Y, Akdal G. Supervised versus home physiotherapy outcomes in stroke patients with unilateral visual neglect: a randomized controlled follow-up study. J Neurol Sci (Turk). 2009;26(3):325-334. Turkish.

37. Hall CD, Heusel-Gillig L, Tusa RJ, Herdman SJ. Efficacy of gaze stability exercises in older adults with dizziness. $J$ Neurol Phys Ther. 2010;34(2):64-69.

38. Hansson EE, Månsson NO, Ringsberg KA, Håkansson A. Falls among dizzy patients in primary healthcare: an intervention study with control group. Int J Rehabil Res. 2008;31(1):51-57.

39. Macias JD, Massingale S, Gerkin RD. Efficacy of vestibular rehabilitation therapy in reducing falls. Otolaryngol Head Neck Surg. 2005;133(3):323-325. 


\section{Publish your work in this journal}

Neuropsychiatric Disease and Treatment is an international, peerreviewed journal of clinical therapeutics and pharmacology focusing on concise rapid reporting of clinical or pre-clinical studies on a range of neuropsychiatric and neurological disorders. This journal is indexed on PubMed Central, the 'PsycINFO' database and CAS.

The manuscript management system is completely online and includes a very quick and fair peer-review system, which is all easy to use. Visit http://www.dovepress.com/testimonials.php to read real quotes from published authors.

Submit your manuscript here: http://www.dovepress.com/neuropsychiatric-disease-and-treatment-journal 